\title{
To the Question about the Nature and Structure of Jupiter's Magnetic Field
}

\author{
Arkadiy Nikolaevich Dmitriev \\ Tyumen Industrial University, Tyumen, Russia \\ Email: dmitriev38@inbox.ru
}

How to cite this paper: Dmitriev, A.N. (2017) To the Question about the Nature and Structure of Jupiter's Magnetic Field. International Journal of Geosciences, 8, 1091-1110.

https://doi.org/10.4236/ijg.2017.89062

Received: August 5, 2017

Accepted: September 16, 2017

Published: September 19, 2017

Copyright $\odot 2017$ by author and Scientific Research Publishing Inc. This work is licensed under the Creative Commons Attribution International License (CC BY 4.0).

http://creativecommons.org/licenses/by/4.0/

(c) (i) Open Access

\begin{abstract}
There was elaborated a method for calculating magnetic fields of the Solar System planets. It is based on the quantum theory of electroconductivity of metals and semiconductors. The latter helps to calculate thermoelectrical processes, always taking place in the bowels of "hot" planets. Main elements of those processes are planetary temperature gradients, thermo electromotive force and radially directed thermoelectrical currents, which are associated with Seebeck effect. Thermo electromotive force causes directional movement of planetary thermoelectrical currents both in metal cores and other conductive shells of planets. Those currents are big and they generate magnetic fields of proportional intensity. The capacities of the calculation method were tested while finding the reason why the Jupiter magnetic field is such complicated. As a result it was specified that the source of the main magnetic field of a planet is its metal core and the source of an additional magnetic field is the layer of liquid metal hydrogen. There was also found the third source of a local magnetic field of low intensity along the circular zone of the equatorial region. The conclusion that the Jupiter's main magnetic field has a polarity opposite to the Earth's one.
\end{abstract}

\section{Keywords}

Thermo EMF, Planetary Thermoelectric Currents, the Main Magnetic Field, Additional Magnetic Field, Reverse the Polarity of the Magnetic Field

\section{Introduction}

Today there is no effective and universal mathematical model to calculate magnetic fields of the Earth, not to mention other planets of the Solar System. Even the most elaborated mechanism of electromagnetic dynamo still needs full mathematical description performed, and it also needs to be confirmed by success- 
ful laboratory experiments.

The physically justified method of calculation magnetic fields of planets, presented in this article, is a solution as a proper model of the magnetic fields of Earth and other planets of the Solar system is still not elaborated. Primary elements of the said method are described in the work of A.N. Dmitriev [1].

The purpose of the present article is to consider the method of calculation magnetic fields of "hot" planets. Its effectiveness and advantages in comparison to the model of hydromagnetic dynamo were proved by finding out the reasons why the Jupiter's magnetic field has such a complicated structure. The method is based on the quantum theory of electroconductivity of metals and semiconductors, which is oriented to calculate mainly thermal processes, always taking place inside the bowels of "hot" planets. Main elements of those processes are planetary geotemperature gradients, thermo EMF and radially directed thermoelectrical currents, which are associated with Seebeck effect. These currents are always in the bowels of "hot" planets, possess an enormous amount of energy, and they generate and maintain magnetic fields for a long time, mostly dipole magnetic field.

\section{Briefly about Basics of Thermoelectrical Model of the Jupiter's Magnetic Field by the Example of Liquid Metal Hydrogen}

Today Jupiter is not studied as good as Earth is. The data that has been being obtained since 1972 using spacecrafts and the Hubble Space Telescope let us describe the inner structure of the planet just in broad outlines. But it is definitely that Jupiter has the most intensive magnetic field in the Solar System. Its intensity on the equator is about $4.2 \mathrm{G}\left(4.2 \times 10^{-4} \mathrm{~T}\right)$ on the visible clouds surface lev$\mathrm{el}$, and it is $14 \mathrm{G}\left(1.4 \times 10^{-3} \mathrm{~T}\right)$ on the Jupiter's pole [2]-[8] that is 12 times more than the magnetic field on the Earth's equator; furthermore, it is even 5 - 10 times more than the polar (dipole) magnetic field of the Earth. There are some theories of the Jupiter's magnetic field nature. The main one is that there must be a dynamo, similar to the Earth's one, but, as scientists believe, the Jupiter's electricity conductor is a mostly hydrogen layer, unlike the Earth's Fe-Ni core [6].

But can we believe this point of view to be the only one right, considering recently achieved modern data? Anyway, to find the answer we must know the inner structure of the planet. It is possible to make a more accurate and modern model of the inner structure of the Jupiter (Figure 1(a)) with the available information, including space exploration, computer modeling of the Jupiter's magnetic field [9] [10], mathematical modeling of helium physical properties at high $p$ and $T$ [11] and physical experiments to study electrical properties of $\mathrm{H}$ and He at high $p$ and $\mathrm{T}$ [12]. In particular, it has a gas layer (atmosphere), a liquid molecular hydrogen layer, a layer of liquid hydrogen with metal properties (hereinafter $\mathrm{Me}_{\mathrm{H}}$ ), stone core of ice and solid rocks [13]. As for the latter, there is 


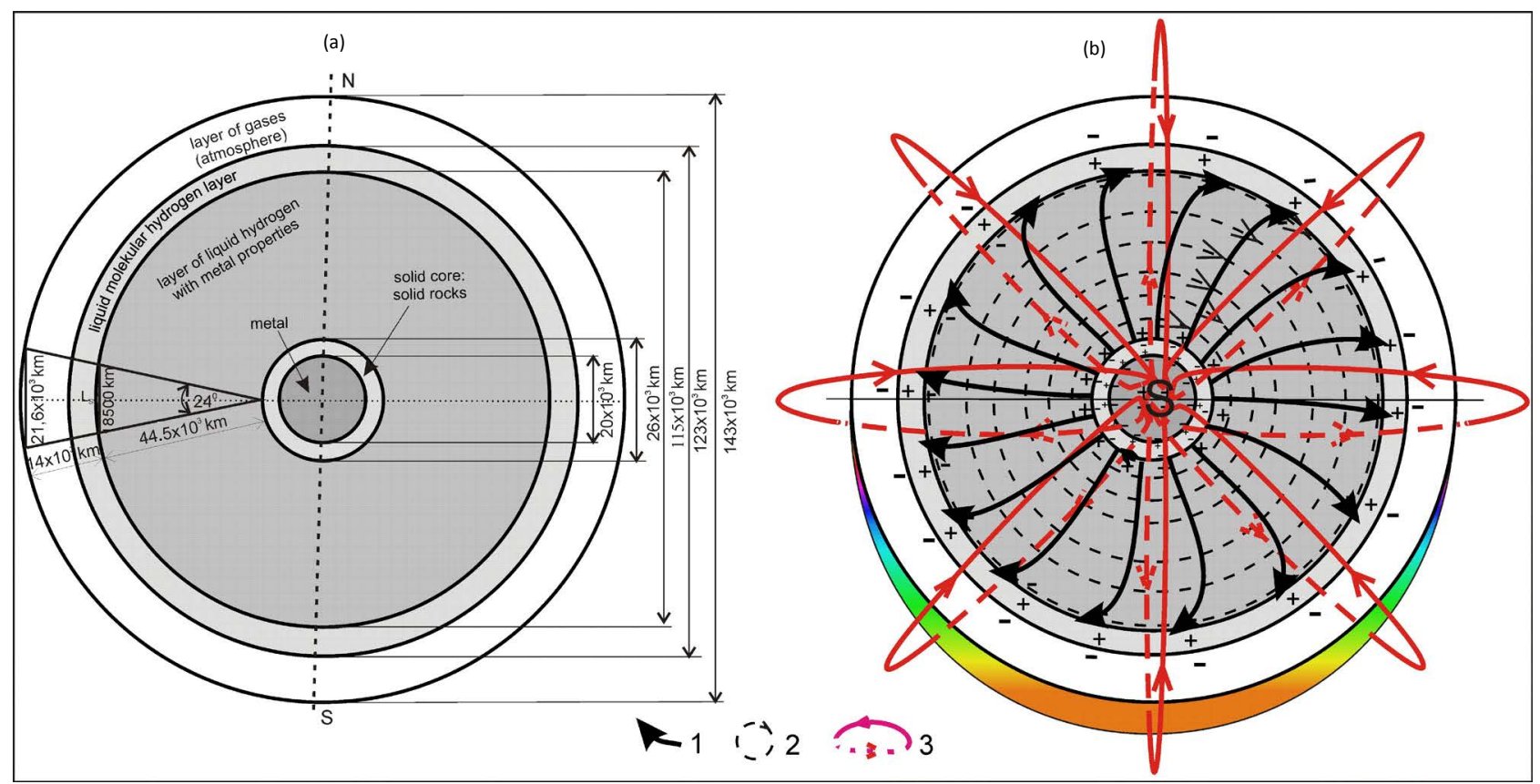

Figure 1. The model of the Jupiter's inner structure and the principal scheme of electrical currents moving in the liquid metal hydrogen layer, generating the Jupiter's magnetic field: (a) spherical five-layer model with the most possible diameters of each layer; (b) magnetic fields are shown as suppositive axonometric projections of a hemisphere with the section in the equator plane. 1-the source of the toroidal magnetic field-a thermoelectric currents; 2-magnetic field lines of the spheroidal toroidal field; 3 -field lines of the poloidal dipole magnetic field.

an assumption that the core's diameter can be 2 times larger than it was considered to be and be $29 \times 10^{3} \mathrm{~km}$ [7], according to the results of a recent computer modeling [9] [10]. Besides, in the center of that core there may be another small inner core of heavy metals, probably iron and nickel [9] [10]. In this case the model of the Jupiter's inner structure can be viewed as a spherical five-layer model.

That five-layer model contains levels which consist of mostly conductive substance and contain electrons of different concentrations. The third layer of liquid metal hydrogen and the metal core should be referred to those levels. At certain favorable conditions those levels are the levels where big thermoelectrical currents can flow, which can both create and maintain the Jupiter's magnetic field for a long time. In particular, planetary temperature gradient, that can maintain difference of temperatures $\Delta T=(20000-10000) \mathrm{K}=10000 \mathrm{~K}$ between the inner and the outer shells, is such a favorable condition for the $\mathrm{Me}_{\mathrm{H}}$ layer [14] [13] [8] [10]. That layer is also characterized by a notable gradient of pressure from 200 $300 \mathrm{GPa}$ (the upper shell) to 4000 - $4500 \mathrm{GPa}$ (the lower shell) [7].

For the radially directed movement of electrons, i.e. thermoelectrical currents, there must be electrical potential gradient of the same orientation. But the latter can happen if there is an external so-called potential-forming factor or, in other words, an external EMF of non-electric origin. In a planet's body function of the latter is performed by the difference o temperatures $\Delta T$, that is radially orien- 
tated, according to the temperature gradient. At the same time, there is the Seebeck effect, which happens when temperature difference $\Delta T$ is attached to the both of the points of an electronic conductor, what causes potential difference $\Delta \varphi_{T}$ between those points because "hot" electrons move to the "cold" point of the conductor [15] [16]:

$$
\Delta \varphi_{T}=\int_{T_{1}}^{T_{2}} \beta \mathrm{d} T
$$

where $\beta$ is temperature coefficient, which is $0.0001 \mathrm{~V} / \mathrm{deg}$ for pure metals and $0.0015 \mathrm{~V} / \mathrm{deg}$ for some semiconductors [16].

Hence, unidirectional effect of the Jupiter's planetary temperature gradient, in the $\mathrm{Me}_{\mathrm{H}}$ layer between its inner and outer spherical borders in particular, makes electric intensity $\boldsymbol{E}_{\mathrm{Me}_{\mathrm{H}}}^{T}$ stay lasting between those borders:

$$
\boldsymbol{E}_{\mathrm{Me}_{\mathrm{H}}}^{T}=\Delta \varphi_{T} / l_{\mathrm{Me}_{\mathrm{H}}}, \mathrm{V} / \mathrm{m} ;
$$

where $l_{\mathrm{Me}_{\mathrm{H}}}$ is the spherical layer thickness of metal hydrogen, $\mathrm{m}$.

The $\mathrm{Me}_{\mathrm{H}}$ layer thickness corresponds to the distance between the solid core surface and the outer core of the layer, it is $44500 \mathrm{~km}$. So, if $\Delta T$ is $10000 \mathrm{~K}$, it defines $\boldsymbol{E}_{\mathrm{Me}_{\mathrm{H}}}^{T}$ as $2.25 \times 10^{-8} \mathrm{~V} / \mathrm{deg}$.

Then $\boldsymbol{E}_{\mathrm{Me}_{\mathrm{H}}}^{T}$ makes free electrons forcibly move in radial direction, that generates flows of spherically directed thermoelectrical currents $\boldsymbol{I}_{\mathrm{Me}_{\mathrm{H}}}$ moving from the lower warmer part of the layer to its cold part. At the same time, both gravitation and inertial Coriolis forces begin to affect electrons. Those forces make electrons change radial direction into the side opposite to rotation, the more intensively the closer to the upper border of the $\mathrm{Me}_{\mathrm{H}}$ layer electrons are (Figure 1(b)). As for gravitational forces, centrifugal force $\boldsymbol{F}_{\text {centr }}=m w^{2} \boldsymbol{R}_{i}$ in particular, the latter always diverts electrons both to the axis of planet's rotation and oppositely (Figure 2(a)). The quality $F_{\text {centr }}$ is proportional to the radius-vector $\boldsymbol{R}_{\boldsymbol{i}}$, which is represented by different lengths of horizontal arrows on Figure 2.

Directed currents of thermoelectrical currents $\boldsymbol{I}_{\mathrm{Me}_{\mathrm{H}}}$ cause toroidal magnetic field inside a spherically enclosed conductor, which is, in its turn, generates a poloidal field, observable beyond that enclosed conductor. But is the $\boldsymbol{I}_{\mathrm{Me}_{\mathrm{H}}}$ energy enough to generate the Jupiter's magnetic field, which is $4 \times 10^{-4} \mathrm{~T}$ intensive on the equator and $1.4 \times 10^{-3} \mathrm{~T}$ intensive on the pole?

To answer this question one should firstly calculate density of the thermoelectrical current $j_{\mathrm{Me}_{\mathrm{H}}}$ that appears just on $1 \mathrm{~m}^{2}$ on the surface of the shell of the $\mathrm{Me}_{\mathrm{H}}$ layer. According to the quantum theory of metal electrical conductivity, current $\boldsymbol{j}$ density value is defined by [16]-[21]:

$$
\boldsymbol{j}_{\mathrm{Me}_{\mathrm{H}}}=e^{2} n \boldsymbol{E}_{\mathrm{Me}_{\mathrm{H}}}^{T} \frac{l}{p_{F}}
$$

where $e$ is effective electron charge, $\mathrm{C}\left(1.6 \times 10^{-19}\right) ; n$ is quantity (concentration) of electrons in a volume unit of a metal conductor, $\mathrm{m}^{-3}$, assuming that metal hydrogen has all the properties of that conductor. 


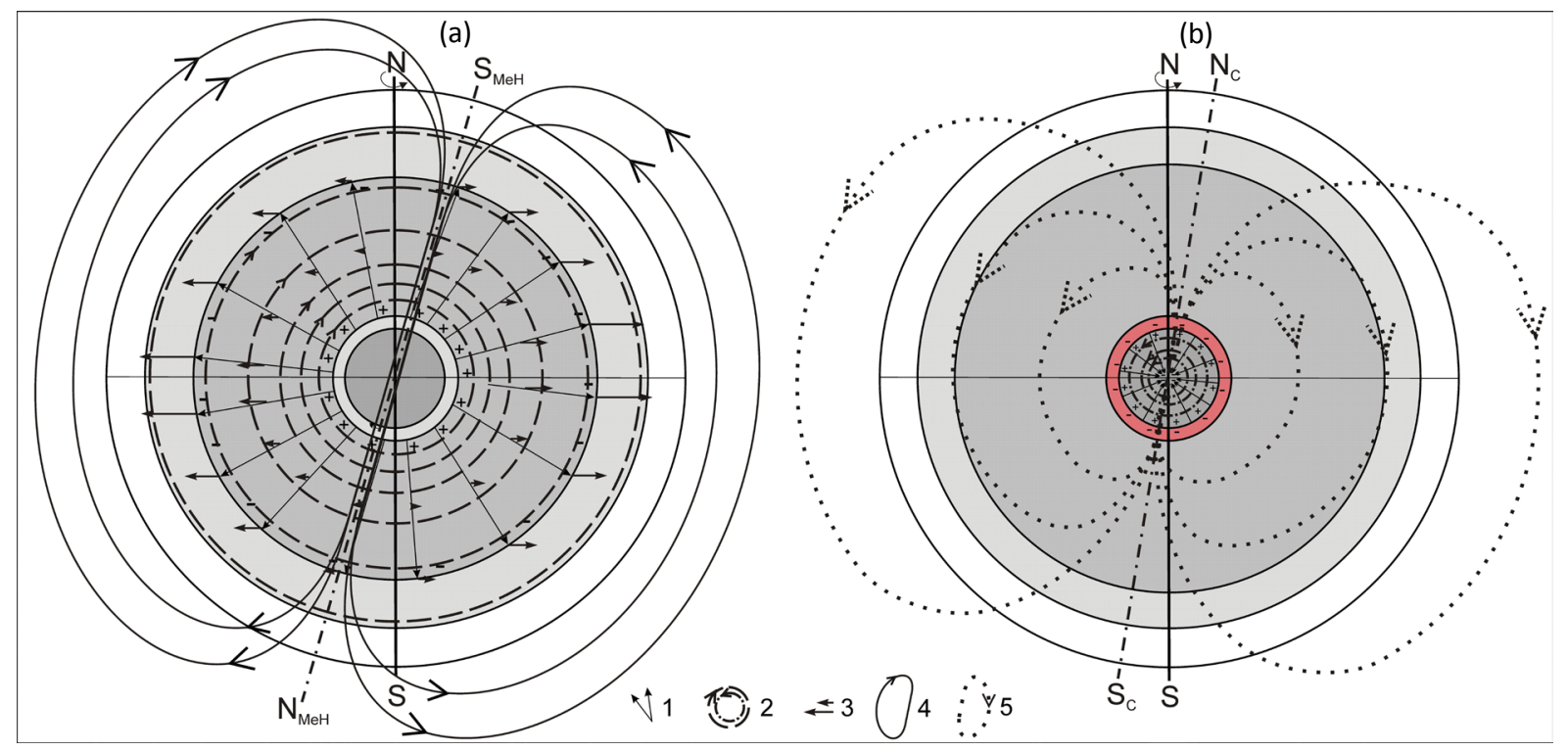

Figure 2. Schemes of the directed flows of thermoelectrical currents: a) unidirectional ones in the liquid metal hydrogen layer and in the Jupiter's metal core, b) currents in the metal core are directed oppositely to the ones in the liquid metal hydrogen layer. 1-vectors of the radially directed thermoelectrical currents in the electrically conductive shells of the planet; 2-magnetic field lines of toroidal fields in the electrically conductive shells of the planet; 3-vectors of the centrifugal force, deflecting electrons to the direction which is natural for the planet rotation axis; 4, 5-magnetic field lines of the poloidal fields of the liquid metal hydrogen layer and of the metal core respectivelly.

Then $n$ is defined by:

$$
n=\left(5 \frac{m_{e}}{\hbar^{2}}\left(3 \pi^{2}\right)^{-2 / 3}\right)^{3 / 5} p^{3 / 5}
$$

where $l$ is the average distance electrons run to the $\boldsymbol{E}_{T}$ electric field between concussions, it is defined by:

$$
l=\frac{\sigma \hbar\left(3 \pi^{2}\right)^{1 / 3}}{e^{2} n^{2 / 3}}, \mathrm{~m}
$$

$m_{e}$ is mass of electron, $9.11 \times 10^{-31} \mathrm{~kg}$;

$\hbar$ is Planck constant, $1.05 \times 10^{-34} \mathrm{~J} \cdot \mathrm{s}$;

$p$ is pressure in the metal hydrogen layer, $\mathrm{P}$;

$\sigma$ is electrical conductivity of the metal hydrogen layer $\mathrm{Me}_{\mathrm{H}}, \mathrm{S} / \mathrm{m}$;

$p_{F}$ is Fermi momentum, which is defined as:

$$
p_{F}=\hbar\left(3 \pi^{2} n\right)^{\frac{1}{3}}
$$

Formula (4) defines concentration of electrons in metals, generally, of great density, whereas density of liquid hydrogen is $70.8 \mathrm{~kg} / \mathrm{m}^{3}$ [22]. Therefore if we take metal hydrogen as liquid metal in (4) we should make a correction for low density of metal hydrogen $b=\rho_{\mathrm{Me}_{\mathrm{H}}} / \rho_{\mathrm{Fe}}$ empirically (Fe is used as most common in cores of planets). Then: 


$$
n=b\left(5 \frac{m_{e}}{\hbar^{2}}\left(3 \pi^{2}\right)^{-2 / 3}\right)^{3 / 5} p^{3 / 5}
$$

If we take boundary pressures in the $\mathrm{Me}_{\mathrm{H}}$ layer from $200 \mathrm{GPa}$ to $4500 \mathrm{GPa}$ considering [7] [13] [23] and use them as substitutes in (7), we will get average concentration of electrons in a unit of layer volume $n=5.64 \times 10^{27} \mathrm{~m}^{-3}$. Constant $b$ in the calculations was taken as $0.009\left(70.8 / 7870 \mathrm{~kg} / \mathrm{m}^{3}\right)$. However despite using the $b$ correction the derived quantity $n$ cannot be objectively used for the $\mathrm{Me}_{\mathrm{H}}$ layer, because average density of Jupiter generally is just $1.326 \mathrm{~g} / \mathrm{cm}^{3}$ [14] [23] [7]. That is why it may be better to use classical electronic theory of metals where moving of electrons obeys the laws of statistical methods and $n$ is determined by formula [16]:

$$
n=\rho \frac{N_{A}}{A}
$$

where $\rho$ is density of metal hydrogen, $70.8 \mathrm{~kg} / \mathrm{m}^{3}$;

$N_{A}$ is Avogadro constant, $6.02 \times 10^{23} \mathrm{~mol}^{-1}$;

$A$ is molar mass of hydrogen, $0.0010079 \mathrm{~kg} / \mathrm{mol}$.

If there is one free electron for an atom, which corresponds to monoatomic hydrogen $\mathrm{H}$, then (8) results in $n=4.23 \times 10^{22} \mathrm{~m}^{-3}$.

At the same time, to calculate $l, \boldsymbol{j}$ and $\boldsymbol{I}_{\mathrm{Me}_{\mathrm{H}}}$, we must know the electrical conductivity $\sigma$ of the $\mathrm{Me}_{\mathrm{H}}$ layer. However this parameter is still unknown. Physical experiments are held nowadays [24] [25] [26] [27], but specific and repeatable results cannot be gained because they cannot be stored for a long time. There are first efforts in mathematical modeling of metal helium, results of which inspire the authors that there may be successful prospering of electrical parameters [11].

That is why we need to use a logical reasoning. The $\mathrm{Me}_{\mathrm{H}}$ layer cannot be superconducting, because it would require temperature close to absolute zero. At the same time that layer cannot be high conductive as usual metals $\left(10^{5}-10^{7}\right.$ $\mathrm{S} / \mathrm{m}$ ), because of its liquid state with extremely low density and, particularly, very high temperature in the planet's body. But the layer can have heightened electrical conductivity $\left(20-10^{3} \mathrm{~S} / \mathrm{m}\right)$ even compared to semiconductors $(0.1-10$ $\mathrm{S} / \mathrm{m})$. So, the start point of electrical conductivity for the $\mathrm{Me}_{\mathrm{H}}$ layer can be, for instance, $\sigma=470 \mathrm{~S} / \mathrm{m}$, low value of which corresponds to the tendency of $\mathrm{H}$ and $\mathrm{He}$ to have quite low electrical conductivity at low $p, T(\sigma=1.94 \mathrm{~S} / \mathrm{m})$, that is proved by a physical experiment [12]. If we put the above value of electrical conductivity into formula (5) and substitute the calculated values of $\boldsymbol{E}_{\mathrm{Me}_{\mathrm{H}}}^{\mathrm{T}}, n$ and $p_{F}$ into (3), we obtain the magnitude of thermoelectrical current density $\boldsymbol{j}_{\mathrm{Me}_{\mathrm{H}}}=1.06 \times 10^{-5} \mathrm{~A} / \mathrm{m}^{2}$.

Then thermoelectrical current $\boldsymbol{I}_{\mathrm{Me}_{\mathrm{H}}}$, that goes through the outer shell $S_{\mathrm{Me}_{\mathrm{H}}}$ of the third $\mathrm{Me}_{\mathrm{H}}$ layer, is defined by:

$$
\boldsymbol{I}_{\mathrm{Me}_{\mathrm{H}}}=\boldsymbol{j} \cdot S_{\mathrm{Me}_{\mathrm{H}}},
$$


where $S_{\mathrm{Me}_{\mathrm{H}}}=4 \pi R_{\mathrm{Me}_{\mathrm{H}}}^{2}$ and it is $4.15 \times 10^{16} \mathrm{~m}^{2}$ at $R_{\mathrm{Me}_{\mathrm{H}}}=5.75 \times 10^{7} \mathrm{~m}$.

Then we can find the final total current magnitude $\boldsymbol{I}_{\mathrm{Me}_{\mathrm{H}}}=4.39 \times 10^{11} \mathrm{~A}$ from (9).

If we know $\boldsymbol{I}_{j u}$ and geometrical parameters of the planet, we should use the Biot-Savart formula to calculate the magnetic field $\boldsymbol{B}_{\mathrm{Me}_{\mathrm{H}}}$ of the $\mathrm{Me}_{\mathrm{H}}$ layer. However the said formula, that describes magnetic induction for a spherical conductor with electric current moving from the sphere center to its outer surface, is unknown to the author. To obtain it we can use the following model: a small spherical conductor with radius $R_{\Sigma}$ is put inside a spherical conductor with radius $d R_{i}$. The currents, moving from the center of the sphere, make a magnetic field inside the volume of the small sphere. This magnetic field is always directed to the small sphere's volume surface tangentially. Then, according to circuital theorem, we get

$$
d \boldsymbol{B}_{j u} \frac{4}{3} \pi d R_{i}^{3}=\frac{\mu_{0}}{4 \pi} \boldsymbol{I}_{i} 4 \pi d R_{i}^{2}
$$

where the $\boldsymbol{I}_{i}$ currents are currents that move through the surface of the small sphere $4 \pi d R_{i}^{2}$. If current spreads over the sphere section evenly we have $\boldsymbol{I}_{i}=\boldsymbol{I}_{\mathrm{Me}_{\mathrm{H}}}\left(\frac{d R_{i}}{R}\right)^{2}$. Hence, shortening and substituting we get Biot-Savart formula for calculating magnetic field induction inside a sphere (metal core). Here it is, rationalized:

$$
d \boldsymbol{B}_{j u}=\frac{3 \mu_{0} \boldsymbol{I}_{\mathrm{Me}_{\mathrm{H}}} d R_{\mathrm{ie}_{\mathrm{H}}}}{4 \pi R^{2}} \quad \text { or } \quad \boldsymbol{B}_{j u}=\frac{3 \mu_{0} \boldsymbol{I}_{\mathrm{Me}_{\mathrm{H}}} R_{\mathrm{Me}_{\mathrm{H}}}}{4 \pi R^{2}} \sin \alpha,
$$

where $R$ is radius of Jupiter, $R_{\mathrm{Me}_{\mathrm{H}}}$ is radius of outer spherical surface of the $\mathrm{Me}_{\mathrm{H}}$ layer, $d \boldsymbol{B}_{j u}=d \boldsymbol{B}_{\mathrm{Me}_{\mathrm{H}}}$. Because of spherical symmetry angle $\alpha=90^{\circ}$ at any point of outer spherical surface when we calculate $\boldsymbol{B}_{\mathrm{Me}_{\mathrm{H}}}$.

When calculating magnetic field on the planet surface, the spherical $\mathrm{Me}_{\mathrm{H}}$ layer, in its turn, depends not on the radius of that layer $R_{\mathrm{Me}_{\mathrm{H}}}$, but on its thickness $R_{\mathrm{Me}_{\mathrm{H}}}$. Then (10) changes as follows:

$$
\boldsymbol{B}_{\mathrm{Me}_{\mathrm{H}}}=\frac{3 \mu_{0} \boldsymbol{I}_{j u} \Delta R_{\mathrm{Me}_{\mathrm{H}}}}{4 \pi R^{2}} \sin \alpha
$$

Putting the appropriate meanings into (11), we can see that magnetic induction $\boldsymbol{B}_{\mathrm{Me}_{\mathrm{H}}}^{e}$ on the equator is $1.15 \times 10^{-3} \mathrm{~T}$ at $1 \mathrm{Rj}=R_{e}=7.15 \times 10^{7} \mathrm{~m}$, while the magnetic induction on the pole $\boldsymbol{B}_{\mathrm{Me}_{\mathrm{H}}}^{p}$ is $1.23 \times 10^{-3} \mathrm{~T}$ at $R=R_{e}=6.68 \times 10^{7} \mathrm{~m}$.

According to the data obtained by spacecrafts via measuring magnetic field, magnetic field changes at the equator from $3.2-4.3 \mathrm{G}$ to $13-14.3 \mathrm{G}$ on the poles (let us take $\boldsymbol{B}_{j u}^{p}$ as $1.4 \times 10^{-3} \mathrm{~T}$ ) [2] [8] [28] [29] [30] [31]. However, it is not always clear from the quoted literature to what point of the Jupiter's equator the measured values $3.2-4.3 \mathrm{G}$ should be referred, whether they should be referred to the Jupiter's surface for $1 \mathrm{Rj}$ or to the remote points for $n \mathrm{Rj}$. As it appears, the most reliable data can be derived from the connection graph $B_{n}=f(n \mathrm{Rj})$, 
where $n$ is measured from 2 to 20 [2]. In particular, the value of $4.2-4.3 \mathrm{G}$ on this graph corresponds to $3 \mathrm{Rj}$ distance. That is why hereinafter we use $\boldsymbol{B}_{j u}^{e}$ which is $4.2 \times 10^{-4} \mathrm{~T}$. It is noteworthy that magnetic field at poles is not homogeneous, it is $1.4 \times 10^{-3} \mathrm{~T}$ on the North pole and $1.07 \times 10^{-3} \mathrm{~T}$ on the South pole of the Jupiter [32].

To watch the Jupiter's magnetic field calculations and its results comfortably here is Table 1 .

It shows that the calculated value of magnetic field on the Jupiter's equator $\boldsymbol{B}_{\mathrm{Me}_{\mathrm{H}}}^{e}$ is almost 3 times more than the measured one $\boldsymbol{B}_{j u}^{e}$, while on the pole the measured magnetic induction $\boldsymbol{B}_{\mathrm{Me}_{\mathrm{H}}}^{p}$ differs from the calculated one $\boldsymbol{B}_{j u}^{p}$ by a

Table 1. Calculation of electrical and magnetic parameters of the Jupiter's metal hydrogen layer.

\begin{tabular}{|c|c|c|c|c|}
\hline Constants and calculated parameters & Measure & Used formulas & & Results of calculations \\
\hline$T$ of the $\mathrm{Me}_{\mathrm{H}}$ layer: the upper/the lower layer borders & $\mathrm{K}$ & & & $10^{4} / 2.0 \times 10^{4}$ \\
\hline Radius of the outer spherical surface of the $\mathrm{Me}_{\mathrm{H}}$ layer, $R_{\mathrm{Mе}_{\mathrm{H}}}$ & $\mathrm{m}$ & & & $5.75 \times 10^{7}$ \\
\hline Thickness of the $\mathrm{Me}_{\mathrm{H}}$ layer, $\Delta R_{\mathrm{Mе}_{\mathrm{H}}}$ & $\mathrm{m}$ & & & $4.45 \times 10^{7}$ \\
\hline $\begin{array}{l}\text { Intensity of the thermofield } \boldsymbol{E}_{\mathrm{Me}_{\mathrm{H}}}^{T} \text { in the } \mathrm{Me}_{\mathrm{H}} \text { layer } \\
\text { when } \Delta T=10000 \mathrm{~K}\end{array}$ & $\mathrm{~V} / \mathrm{m}$ & $\begin{array}{l}\boldsymbol{E}_{\mathrm{Me}_{\mathrm{H}}}^{T}=\beta_{*} \Delta T / \Delta R_{\mathrm{Me}_{\mathrm{H}}}, \\
\text { where } \beta=0.0001 \mathrm{~V} / \mathrm{deg}\end{array}$ & $(2)$ & $2.25 \times 10^{-8}$ \\
\hline Area of the spherical surface $S_{\mathrm{Me}_{\mathrm{H}}}$ with radius $R_{\mathrm{Me}_{\mathrm{H}}}$ & $\mathrm{m}^{2}$ & $S_{\mathrm{Me}_{\mathrm{H}}}=4 \pi R_{\mathrm{Me}_{\mathrm{H}}}^{2}$ & & $4.15 \times 10^{16}$ \\
\hline Core radius, $R_{C}$ & $\mathrm{~m}$ & & & $1.3 \times 10^{7}$ \\
\hline Equatorial radius of Jupiter, $R_{e}$ & $\mathrm{~m}$ & & & $7.15 \times 10^{7}$ \\
\hline Polar radius of Jupiter, $R_{p}$ & $\mathrm{~m}$ & & & $6.68 \times 10^{7}$ \\
\hline Planck's constant, $\hbar$ & $\mathrm{J} \cdot \mathrm{s}$ & & & $1.05 \times 10^{-34}$ \\
\hline Electron charge, $e$ & $\mathrm{C}$ & & & $1.6 \times 10^{-19}$ \\
\hline Electron mass, $m_{e}$ & $\mathrm{~kg}$ & & & $9.1 \times 10^{-31}$ \\
\hline electrical conductivity of the $\mathrm{Me}_{\mathrm{H}}$ layer, $\sigma$ & $\mathrm{S} / \mathrm{m}$ & & & 470 \\
\hline $\begin{array}{l}\text { Concentration of electrons in the } \mathrm{Me}_{\mathrm{H}} \text { layer (calculated } \\
\text { by the formula for metals), medium, } n\end{array}$ & $\mathrm{~m}^{-3}$ & $n=b\left(5 \frac{m_{e}}{\hbar^{2}}\left(3 \pi^{2}\right)^{-2 / 3}\right)^{3 / 5} p^{3 / 5}$ & (7) & $5.64 \times 10^{27}$ \\
\hline $\begin{array}{l}\text { Concentration of electrons in the } \mathrm{Me}_{\mathrm{H}} \text { layer (calculated by } \\
\text { formula, considering density } \mathrm{H}_{\text {metall }} \rho=70.8 \mathrm{~kg} / \mathrm{m}^{3} \text { ) }\end{array}$ & $\mathrm{m}^{-3}$ & $n=\rho \frac{N_{A}}{A}$ & $(8)$ & $4.23 \times 10^{22}$ \\
\hline Fermi momentum, $p_{F}$ & $\mathrm{~m} \cdot \mathrm{kg} / \mathrm{s}$ & $p_{F}=\hbar\left(3 \pi^{2} n\right)^{1 / 3}$ & $(6)$ & $1.14 \times 10^{-26}$ \\
\hline Electron mean free path, 1 & $\mathrm{~nm}$ & $l=\frac{\sigma \hbar\left(3 \pi^{2}\right)^{1 / 3}}{e^{2} n^{2 / 3}} 10^{9}$ & $(5)$ & 49.3 \\
\hline Current density, $\boldsymbol{j}_{\mathrm{мен}_{\mathrm{H}}}$ & $\mathrm{A} / \mathrm{m}^{2}$ & $\boldsymbol{j}_{\mathrm{MeH}_{\mathrm{H}}}=e^{2} n \boldsymbol{E}_{\mathrm{MeH}_{\mathrm{H}}}^{T} \frac{l}{p_{F}}$ & (3) & $1.06 \times 10^{-5}$ \\
\hline $\begin{array}{l}\text { Total current value of the } \mathrm{Me}_{\mathrm{H}} \text { layer, through the } S_{\mathrm{Me}_{\mathrm{H}}} \\
\text { surface, } \boldsymbol{I}_{\mathrm{Me}_{\mathrm{H}}}\end{array}$ & A & $\boldsymbol{I}_{\mathrm{Me}_{\mathrm{H}}}=\boldsymbol{j}_{\mathrm{Me}_{\mathrm{H}}} S_{\mathrm{Me}_{\mathrm{H}}}$ & (9) & $4.39 \times 10^{11}$ \\
\hline $\begin{array}{l}\text { Calculated magnetic induction on the Jupiter's pole } \boldsymbol{B}_{\mathrm{Me}_{\mathrm{H}}}^{p} / \\
\text { Measured magnetic induction on the pole } \boldsymbol{B}_{j u}^{p}\end{array}$ & $\mathrm{~T}$ & $\boldsymbol{B}_{\mathrm{Me}_{\mathrm{H}}}^{p}=\frac{3 \mu_{0} \boldsymbol{I}_{\mathrm{Me}_{\mathrm{H}}} \Delta R_{\mathrm{Me}_{\mathrm{H}}}}{4 \pi R_{p}^{2}} \sin \alpha$ & (11) & $\begin{array}{l}1.23 \times 10^{-3} \\
/ 1.4 \times 10^{-3}\end{array}$ \\
\hline $\begin{array}{l}\text { Calculated magnetic induction on the Jupiter's equator } \boldsymbol{B}_{\mathrm{M}_{\mathrm{H}}}^{e} / \\
\text { Measured magnetic induction on the equator } \boldsymbol{B}_{j u}^{e}\end{array}$ & $\mathrm{~T}$ & $\boldsymbol{B}_{\mathrm{Me}_{\mathrm{H}}}^{e}=\frac{3 \mu_{0} \boldsymbol{I}_{\mathrm{Me}_{\mathrm{H}}} \Delta R_{\mathrm{Me}_{\mathrm{H}}}}{4 \pi R_{e}^{2}} \sin \alpha$ & (11) & $\begin{array}{l}1.15 \times 10^{-3} \\
14.2 \times 10^{-4}\end{array}$ \\
\hline
\end{tabular}


little bit more than $12 \%$. However this quite coincident result cannot be taken as the final one, because the planet has additional resources of magnetic fields, metal core in particular.

\section{Thermoelectrical Currents of the Jupiter's Metal Core Form Its Main Dipole Magnetic Field}

To calculate the magnetic field produced by the core its main physical parameters should be defined: a) difference of temperatures between the planet's center and the core's outer shell $\Delta T_{O}$ predicted by the known data [9] [10] [13] [14] and b) electroconductivity $\sigma$ ranging from 0.1 to 1 million S/m [33] [34] [35].

According to p. a), let us take $T_{1}=20000 \mathrm{~K}$ at the outer border of the core and $T_{2}=23000 \mathrm{~K}$ in the center of the corner, that will make $\Delta T_{C}$ be $3000 \mathrm{~K}$. Comparing to thermal conductivity of pure metals this value can be real, if we agree that the planet's core can consist predominantly of iron carbide $\mathrm{Fe}_{7} \mathrm{C}_{3}$ just like on Earth [36] with available data of abnormally high $p, T$ [37]. According to $\mathrm{p}$. b) let us take the electroconductivity of the Jupiter's core $\sigma=1.1 \times 10^{5} \mathrm{~S} / \mathrm{m}$, which is close to the minimal Earth one and can be explained due to a great amount of carbon.

Now let us calculate electric and magnetic parameters of the solid core, which has temperature dynamics. To do this, let us use the mentioned formulas $(2-3$, $5-7,9,11)$.

In particular, we must use the initial data when calculating:

$T$ of the metal core layer: outer shell/core center - 20000/23000 K;

Metal core radius, $R_{C}=1.0 \times 10^{7} \mathrm{~m}$;

Radius of the core with the rock shell, $R_{C+S}=1.3 \times 10^{7} \mathrm{~m}$;

Area of the core spherical surface with radius $S_{C}=4 \pi R_{C}^{2}=1.26 \times 10^{15} \mathrm{~m}$;

Equatorial radius of Jupiter, $R_{e}=7.15 \times 10^{7} \mathrm{~m}$;

Polar radius of Jupiter, $R_{p}=6.68 \times 10^{7} \mathrm{~m}$;

Core electrical conductivity, $\sigma=110000 \mathrm{~S} / \mathrm{m}$;

Then

Thermofield intensity $E_{C}^{T}$ in the core when $\Delta T_{C}=3000 \mathrm{~K}$, can be found from the following formula:

$$
E_{C}^{T}=\beta_{*} \Delta T_{C} / R_{C}
$$

where $\beta=0.0001 \mathrm{~V} / \mathrm{deg}$.

From the formula (7) is concentration of electrons in the core when pressure is $4.5 \times 10^{12} \mathrm{GPa}, n=1.48 \times 10^{30} \mathrm{~m}^{-3}$; from the formulas $(6,5)$ is Fermi momentum and electron mean free path, respectively $p_{F}=3.72 \times 10^{-24} \mathrm{~m} \cdot \mathrm{kg} / \mathrm{s}$, $l=0.0108 \mathrm{~nm}$. To calculate the current density, use the formula:

$$
\boldsymbol{j}_{C}=e^{2} n E_{C}^{T} \frac{l}{p_{F}},
$$

which is defined by a magnitude of $3.3 \times 10^{-3} \mathrm{~A} / \mathrm{m}^{2}$. In its turn, total current value through its outer surface $S_{C}, \boldsymbol{I}_{C}$ calculated by the formula: 


$$
\boldsymbol{I}_{C}=\boldsymbol{j}_{C} S_{C}
$$

Then find the magnetic induction on the Jupiter's pole $\boldsymbol{B}_{C}^{p}$ :

$$
\boldsymbol{B}_{C}^{p}=\frac{3 \mu_{0} \boldsymbol{I}_{C} R_{C}}{4 \pi R_{p}^{2}} \sin \alpha
$$

and magnetic induction on the Jupiter's equator $\boldsymbol{B}_{C}^{e}$ :

$$
\boldsymbol{B}_{C}^{e}=\frac{3 \mu_{0} \boldsymbol{I}_{C} R_{C}}{4 \pi R_{e}^{2}} \sin \alpha,
$$

which are defined by $2.79 \times 10^{-3} \mathrm{~T}$ and $2.43 \times 10^{-3} \mathrm{~T}$ respectively.

For the readers' convenience, all the calculations are presented in the compact Table 2.

Table 2 shows that the calculated Jupiter's core magnetic field on the pole $\boldsymbol{B}_{C}^{p}$

\begin{tabular}{|c|c|c|c|c|}
\hline Constants and calculated parameters & Measure & Used formulas & & Results of calculations \\
\hline$T$ of the metal core layer: outer shell/core center & $\mathrm{K}$ & & & $20000 / 23000$ \\
\hline Metal core radius, $R_{C}$ & $\mathrm{~m}$ & & & $1.0 \times 10^{7}$ \\
\hline Radius of the core with the rock shell, $R_{C+S}$ & $\mathrm{~m}$ & & & $1.3 \times 10^{7}$ \\
\hline $\begin{array}{l}\text { Thermofield intensity } E_{C}^{T} \text { in the core } \\
\text { when } \Delta T_{C}=3000 \mathrm{~K}\end{array}$ & $\mathrm{~V} / \mathrm{m}$ & $\begin{array}{l}E_{C}^{T}=\beta_{*} \Delta T_{C} / R_{C} \\
\text { where } \beta=0.0001 \mathrm{~V} / \mathrm{deg}\end{array}$ & (2) & $3.0 \times 10^{-8}$ \\
\hline Area of the core spherical surface with radius $R_{C}$ & $\mathrm{~m}^{2}$ & $S_{C}=4 \pi R_{C}^{2}$ & & $1.26 \times 10^{15}$ \\
\hline Equatorial radius of Jupiter, $R_{e}$ & $\mathrm{~m}$ & & & $7.15 \times 10^{7}$ \\
\hline Polar radius of Jupiter, $R_{p}$ & $\mathrm{~m}$ & & & $6.68 \times 10^{7}$ \\
\hline Planck's constant,$\hbar$ & $\mathrm{J} \cdot \mathrm{s}$ & & & $1.05 \times 10^{-34}$ \\
\hline Electron charge, $e$ & $\mathrm{C}$ & & & $1.6 \times 10^{-19}$ \\
\hline Electron mass, $m_{e}$ & $\mathrm{~kg}$ & & & $9.1 \times 10^{-31}$ \\
\hline Core electrical conductivity, $\sigma$ & $\mathrm{S} / \mathrm{m}$ & & & 110000 \\
\hline $\begin{array}{l}\text { Concentration of electrons in the core when pressure is } \\
4.5 \times 10^{12} \mathrm{GPa}, n\end{array}$ & $\mathrm{~m}^{-3}$ & $n=b\left(5 \frac{m_{e}}{\hbar^{2}}\left(3 \pi^{2}\right)^{-2 / 3}\right)^{3 / 5} p^{3 / 5}$ & (7) & $1.48 \times 10^{30}$ \\
\hline Fermi momentum, $p_{F}$ & $\mathrm{~m} \cdot \mathrm{kg} / \mathrm{s}$ & $p_{F}=\hbar\left(3 \pi^{2} n\right)^{1 / 3}$ & (6) & $3.72 \times 10^{-24}$ \\
\hline Electron mean free path , $l$ & $\mathrm{~nm}$ & $l=\frac{\sigma \hbar\left(3 \pi^{2}\right)^{1 / 3}}{e^{2} n^{2 / 3}} 10^{9}$ & (5) & 0.0108 \\
\hline Current density, $\boldsymbol{j}_{C}$ & $\mathrm{~A} / \mathrm{m}^{2}$ & $\boldsymbol{j}_{C}=e^{2} n E_{C}^{T} \frac{l}{p_{F}}$ & (3) & $3.3 \times 10^{-3}$ \\
\hline Total current value through its outer surface $S_{C}, I_{C}$ & A & $\boldsymbol{I}_{C}=\boldsymbol{j}_{C} S_{C}$ & (9) & $4.15 \times 10^{12}$ \\
\hline $\begin{array}{l}\text { Magnetic induction on the Jupiter's pole } \boldsymbol{B}_{C}^{p} / \\
\text { Measured magnetic induction on the pole } \boldsymbol{B}_{j u}^{p}\end{array}$ & $\mathrm{~T}$ & $\boldsymbol{B}_{C}^{p}=\frac{3 \mu_{0} \boldsymbol{I}_{C} R_{\mathrm{C}}}{4 \pi R_{p}^{2}} \sin \alpha$ & (11) & $2.79 \times 10^{-3} / 1.4 \times 10^{-3}$ \\
\hline $\begin{array}{l}\text { Magnetic induction on the Jupiter's equator } \boldsymbol{B}_{C}^{e} / \\
\text { Measured magnetic induction on the equator } \boldsymbol{B}_{j u}^{e}\end{array}$ & $\mathrm{~T}$ & $\boldsymbol{B}_{C}^{e}=\frac{3 \mu_{0} \mathbf{I}_{C} R_{\mathrm{C}}}{4 \pi R_{e}^{2}} \sin \alpha$ & (11) & $2.43 \times 10^{-3} / 4 \times 10^{-4}$ \\
\hline
\end{tabular}
is 2 times more that the measured one $\boldsymbol{B}_{j u}^{p}$. At the same time that magnetic

Table 2. Calculation of electrical and magnetic parameters of the Jupiter's core. 
field on the equator $\boldsymbol{B}_{C}^{e}$ is now 6.1 times more than the measured one $\boldsymbol{B}_{j u}^{e}$. If we suppose that both thermoelectrical currents of the core and of the liquid metal hydrogen layer are directed to the surface of the planet, then the calculated total magnetic fields on the pole and on the equator are $\boldsymbol{B}_{j u}^{p p}=\boldsymbol{B}_{\mathrm{Me}_{\mathrm{H}}}^{p}+\boldsymbol{B}_{C}^{p}=$ $4.01 \times 10^{-3} \mathrm{~T}$ and $\boldsymbol{B}_{j u}^{e e}=\boldsymbol{B}_{\mathrm{Me}_{\mathrm{H}}}^{e}+\boldsymbol{B}_{\mathrm{C}}^{e}=3.58 \times 10^{-3} \mathrm{~T}$ respectively. However these values are way greater than the magnetic fields, measured on the Jupiter's pole and equator. That may be because there are some mistakes in the calculation or because there are thermoelectrical currents moving in the opposite directions.

The latter is possible if the outer rock shell of the Jupiter's core is not just a transitive zone but a radiation zone, where the temperature of rocks is maximum towards the inner core and the $\mathrm{Me}_{\mathrm{H}}$ layer, just like on Earth. In this case thermoelectrical current of the metal core must be directed to its center (Figure 2(b)), and the total Jupiter's magnetic field can be defined by the residual $\boldsymbol{B}_{j u}^{p p}=\boldsymbol{B}_{\mathrm{Me}_{\mathrm{H}}}^{p}+\left(-\boldsymbol{B}_{C}^{p}\right)=-1.56 \times 10^{-3} \mathrm{~T}$, which is close to the measured $\boldsymbol{B}_{j u}^{p}$ by modulus. In its turn, $\boldsymbol{B}_{j u}^{e e}=\boldsymbol{B}_{\mathrm{Me}_{\mathrm{H}}}^{e}+\boldsymbol{B}_{C}^{e}$ is $-1.29 \times 10^{-3} \mathrm{~T}$.

As we can see, the calculated total magnetic fields are negative because $\left|-\boldsymbol{B}_{C}^{p}\right|>\boldsymbol{B}_{\mathrm{Me}_{\mathrm{H}}}^{p}$ and $\left|-\boldsymbol{B}_{C}^{e}\right|>\boldsymbol{B}_{\mathrm{Me}_{\mathrm{H}}}^{e}$. Hence thermoelectrical current of the core, depending on its direction, determines locations of the $\mathrm{N}$ and $\mathrm{S}$ poles of the Jupiter's magnetic field. In particular, as it is shown on the Figure 2(b), the latter coincide with the planet's geographical poles of the same names. It is known that at the present time the orientation of the poles of the Jupiter's magnetic field is opposite to the orientation of the poles the Earth's magnetic field, that was previously found by spacecrafts Pioneer 10 and Pioneer 11 and other [7].

Earth is now in the state of planetary warming, caused by flows of the core and low mantel's thermoelectrical currents moving to the same direction of the Earth's surface. Because of the oppositely directed thermocurrents of the core and of the metal hydrogen layer, Jupiter now is in the state of planetary cooling. This is proved by research showing that the Earth's inner core now tends to cool down at $50 \mathrm{~K} / 10^{9}$ years [38], i.e. $7.2^{\circ} \mathrm{C} / 10^{9}$ years. And this is possible when thermoelectrical currents of the core leave it and begin moving to the lower mantel.

Let us look at the calculated magnetic induction on the equator $\boldsymbol{B}_{j u}^{e e}$ again, it looks like a glaring error in calculations that its value differs almost 6 times from the measured one $\boldsymbol{B}_{j u}^{e}$. However, there is data from Pioneer-10 showing that magnetic field density on the equator at a distance of $3 \mathrm{Rj}$ is about $4.2 \mathrm{G}$ [2]. Therefore magnetic induction of the $\mathrm{Me}_{\mathrm{H}}$ layer $\boldsymbol{B}_{\mathrm{Me}_{\mathrm{H}}}^{e}$ and magnetic induction of the metal core $\boldsymbol{B}_{C}^{e}$ should be recalculated at a distance of three radii of Jupiter. Using formula (11) again we get $\boldsymbol{B}_{\mathrm{Me}_{\mathrm{H}}}^{e}=1.27 \times 10^{-4} \mathrm{~T}$ and $\boldsymbol{B}_{C}^{e}=-2.7 \times 10^{-4} \mathrm{~T}$. If we sum up these components considering the sign of $\boldsymbol{B}_{C}^{e}$, we get a rough magnitude $\boldsymbol{B}_{j u}^{e}=-1.43 \times 10^{-4} \mathrm{~T}$ at a distance of $3 \mathrm{Rj}$, which is almost 3 times less than the calculated one $\boldsymbol{B}_{j u}^{e}$. This difference is quite insignificant, because the existing data of almost all the Jupiter's parameters is approximate. That is why the value $\boldsymbol{B}_{j u}^{e e}=-1.29 \times 10^{-3} \mathrm{~T}$ at $1 \mathrm{Rj}$ should be regarded as quite admissible and close to the real one. But summing up $\boldsymbol{B}_{\mathrm{Me}_{\mathrm{H}}}^{e}$ and $\boldsymbol{B}_{\mathrm{C}}^{e}$ by modulus gives a value of magnetic induction at a distance of $3 \mathrm{Rj}$ as $3.98 \times 10^{-4} \mathrm{~T}$, which is 
quite close to the calculated one $4.2 \times 10^{-4} \mathrm{~T}$. The latter should be regarded as a coinsidence.

\section{Local Circular Magnetic Field of the Jupiter's Equatorial Band}

Aside from the studied autonomous sources of the Jupiter's core and $\mathrm{Me}_{\mathrm{H}}$ layer own magnetic fields, there is at least one more source that can be related to the central part of the planet-equatorial band, which rotates with increased velocity (rotation period is 9 hours 50 minutes and 30 seconds) in comparison to other sectors of the planet, which rotation period is 9 hours 55 minutes and 41 seconds [39].

The increased velocity of the gas clouds is obviously transmitted to the $\mathrm{Me}_{\mathrm{H}}$ layer and to some part of the liquid metal hydrogen layer because of viscosity of gases and liquids. If we suppose that the $\mathrm{Me}_{\mathrm{H}}$ layer viscosity is not great, then three spherical layers can be involved into the equatorial zone as a sector, which geometrical dimensions are shown on the Figure 1(a). Electrical current occurs only in the sectoral part of the $\mathrm{Me}_{\mathrm{H}}$ layer because of the spinning free electrons, that is why it is possible to find current density $\boldsymbol{j}_{e z}$ and amperage $\boldsymbol{I}_{e z}$ for this part of the $\mathrm{Me}_{\mathrm{H}}$ layer [16] [40]:

$$
\boldsymbol{j}_{e z}=\rho_{e z} v,
$$

where $\rho_{e z}$ is volume electric charge density, $\mathrm{C} / \mathrm{m}^{3}$, it can be defined by:

$$
\rho_{e z}=e n
$$

When we know the electron charge $e$ and the previously calculated by the (8) formula electrons concentration per unit volume for the $\mathrm{Me}_{\mathrm{H}}$ layer and calculate linear velocity of the sector for its medial part, we get $\boldsymbol{j}_{e z}=4.23 \times 10^{7} \mathrm{~A} / \mathrm{m}^{2}$ from the (12) formula. In its turn, current value can be found from:

$$
\boldsymbol{I}_{e z}=\boldsymbol{j}_{e z} S_{e z},
$$

where $S_{e z}$ is the section of the spherical sectoral circle in the $\varphi$ angle alignment. Can be found from:

$$
S_{e z}=R_{e z} L_{S} \sin \left(\frac{\pi}{180} \varphi\right)
$$

where $R_{e z}$ is radius of the equatorial band sector with maximum rotation. It is $4.45 \times 10^{7} \mathrm{~m}$, what is equal to the $\mathrm{Me}_{\mathrm{H}}$ layer's thickness;

$L_{S}$ is the chord of the $L_{S}$ sector (see Figure $1(\mathrm{a})$ ), which is $18.5 \times 10^{7} \mathrm{~m}$;

$\varphi$ is the central angle of the Jupiter's equatorial band visibility, deg.

Having substituted the above numbers into (15) we can derive the value of the current in the $\mathrm{Me}_{\mathrm{H}}$ layer sectoral circle from (14), $\boldsymbol{I}_{e z}=6.16 \times 10^{19} \mathrm{~A}$. In its turn, magnetic induction on the Jupiter's equator $\boldsymbol{B}_{e z}^{e}$ can be defined from [15] [16]:

$$
\boldsymbol{B}_{e z}^{e}=\frac{\mu_{0} e n S_{e z}}{4 \pi\left(R_{e}-R_{e z}\right)^{2}} \sin \alpha
$$


Its value turned out to be $3.14 \times 10^{-2} \mathrm{~T}$, that is more than 22 times greater than the calculated $\boldsymbol{B}_{j u}^{e}$ on the planet's equator. It definitely indicates that the $\mathrm{Me}_{\mathrm{H}}$ layer cannot be concatenated to the upper part of the planet's equatorial band to the entire depth. That is why we can suppose that because of the harder condition of the $\mathrm{Me}_{\mathrm{H}}$ layer (increased density) concatenation can be accepted only within its thickness $d_{e z}$ not more than $250 \mathrm{~m}$. Then, having calculated $\boldsymbol{j}_{e z}^{\prime}$, $S_{e z}^{\prime}$ and $\boldsymbol{I}_{e z}^{\prime}$ parameters according to the above formulas we can find the value of the magnetic field for the sectoral plate circle from:

$$
\boldsymbol{B}_{d}^{e}=\frac{\mu_{0} e n S_{e z}^{\prime}}{4 \pi\left(R_{e}-R_{\mathrm{Me}_{\mathrm{H}}}\right)^{2}} \sin \alpha
$$

This magnitude is $1.42 \times 10^{-6} \mathrm{~T}$ on the equator, at the same time $\boldsymbol{B}_{d}^{p}$ on the pole is $3.58 \times 10^{-8} \mathrm{~T}$, if $\left(R_{e}-R_{\mathrm{Me}_{\mathrm{H}}}\right)^{2}$ would be changed into $R_{d}^{2}=R_{e}^{2}+R_{p}^{2}$ in (17). The gathered constituents of magnetic field $\boldsymbol{B}_{d}^{e}$ and $\boldsymbol{B}_{d}^{p}$ for the spherical circle plate of the $\mathrm{Me}_{\mathrm{H}}$ layer are way less than the calculated values of the Jupiter's magnetic fields, so they can be related as contingently real. First, this magnetic field is narrowly located along the circle, because at such distances as $1 \mathrm{Rj}$ the constituents $\boldsymbol{B}_{d}^{e}$ and $\boldsymbol{B}_{d}^{p}$ tend to zero. At the same time, the value of the current $\boldsymbol{I}_{e z}^{\prime}$ is $10^{3}-10^{4}$ times greater than the currents $\boldsymbol{I}_{\mathrm{Me}_{\mathrm{H}}}$ of the $\mathrm{Me}_{\mathrm{H}}$ layer and the $\boldsymbol{I}_{C}$ core. It clarifies the reason why there is such colossal energy of lightning discharges, that can be observed in the middle part of Jupiter and are several times more powerful than the Earth's ones [41]. Actually, the calculations show that the thermocurrents of the Earth's core are not greater than 3.37 $\times 10^{9} \mathrm{~A}[1]$. Besides, characteristic instability of the way the equatorial band rotates toward the neighbor zones is an obvious cause of equatorial jerks.

The calculations of the magnetic field for the sectoral plate circle are brought together into Table 3 for the results to be easily accessible.

As for the direction of the vector of a rotating circle magnetic induction, according to the right-hand rule, it is the same as the direction of the planet's core magnetic field, i.e. lines of magnetic induction comes out of the North pole and go to the South pole (Figure 3).

\section{Structure of the Total Jupiter's Magnetic Field}

There are still studied only three autonomic Jupiter's magnetic fields with different directions of their field lines, and it is quite interesting to predict the structure of total magnetic field $\boldsymbol{B}_{j u}$. The latter is determined by the orientation of resultant vectors $\boldsymbol{B}_{1}$ and $\boldsymbol{B}_{2}$ of the magnetic induction when summing up the vectors of the $\mathrm{Me}_{\mathrm{H}}$ layer magnetic field $D_{1}$ and of the core magnetic field $C_{1}$ and, respectively, $D_{2} C_{2}$ in the North half of Jupiter (Figure 3).

It is clear that $\boldsymbol{B}_{1}$ and $\boldsymbol{B}_{2}$ vectors extend field lines oppositely to the North pole. Otherwise, the resultant vectors of magnetic induction $\boldsymbol{B}_{3}$ and $\boldsymbol{B}_{4}$ at summing up the $D_{3} C_{3}$ vectors and the $D_{4} C_{4}$ respectively in the South half of the planet draw the field lines to the South pole. As a result, the external outline of the resulting 
Table 3. Calculation of electrical and magnetic parameters of the equatorial circular $\mathrm{Me}_{\mathrm{H}}$ layer of Jupiter.

\begin{tabular}{|c|c|c|c|c|}
\hline Constants and calculated parameters & Measure & Used formulas & & Results of calculations \\
\hline $\begin{array}{l}\text { Radius of the equatorial band sector with maximum rotation } \\
R_{e z}=R_{\mathrm{Me}_{\mathrm{H}}}\end{array}$ & $\mathrm{m}$ & & & $4.45 \times 10^{7}$ \\
\hline Full core radius (metal core + stone rocks layer), $R_{c}$ & $\mathrm{~m}$ & & & $1.3 \times 10^{7}$ \\
\hline $\begin{array}{l}\text { Medium sector radius, with medium rotation velocity } \\
\text { of the } \mathrm{Me}_{\mathrm{H}} \text { layer }\end{array}$ & $\mathrm{m}$ & $R_{\text {mid }}=\frac{R_{e z}}{2}+R_{c}$ & & $3.53 \times 10^{7}$ \\
\hline Central angle of visibility of the Jupiter's equatorial band, $\varphi$ & deg. & & & 24 \\
\hline Chord of the sector $L_{S}($ check Figure $1(\mathrm{a}))$ & $\mathrm{m}$ & & & $18.5 \times 10^{7}$ \\
\hline $\begin{array}{l}\text { Section of the spherical sectoral circle in the angle } \varphi \\
\text { alignment, } S_{e z}\end{array}$ & $\mathrm{~m}^{2}$ & $S_{e z}=R_{e z} L_{S} \sin \left(\frac{\pi}{180} \varphi\right)$ & (15) & $1.67 \times 10^{14}$ \\
\hline $\begin{array}{l}\text { Rotation period of the equatorial band/ rotation period } \\
\text { of segments, } T_{1} / T_{2}\end{array}$ & s & $\begin{array}{l}9 \mathrm{~h} .50 \mathrm{~min} .30 \mathrm{~s} \\
/ 9 \mathrm{~h} .55 \mathrm{~min} .41 \mathrm{~s}\end{array}$ & & $35741 / 35430$ \\
\hline Relative velocity of the sector plane with section $S_{e z,} V$ & $\mathrm{~m} / \mathrm{c}$ & $v=2 \pi R_{\text {mid }}\left(\frac{1}{T_{2}}-\frac{1}{T_{1}}\right)$ & & 54.4 \\
\hline Electron charge, $e$ & $\mathrm{C}$ & & & $1.6 \times 10^{-19}$ \\
\hline Concentration of electrons in the $\mathrm{Me}_{\mathrm{H}}$ layer sector, $n$ & $\mathrm{~m}^{-3}$ & $n=\rho \frac{N_{A}}{A}$ & (8) & $4.23 \times 10^{22}$ \\
\hline Electrical charge bulk density, $\rho_{e z}$ & $\mathrm{C} / \mathrm{m}^{3}$ & $\rho_{e z}=e n$ & (13) & $6.77 \times 10^{3}$ \\
\hline Current density, $\boldsymbol{j}_{e z}$ & $\mathrm{~A} / \mathrm{m}^{2}$ & $\boldsymbol{j}_{e z}=\rho_{e z} v$ & (12) & $3.68 \times 10^{5}$ \\
\hline Total current through the sector $S_{e z}$ section, $\boldsymbol{I}_{e z}$ & A & $\boldsymbol{I}_{e z}=\boldsymbol{j}_{e z} S_{e z}$ & (14) & $6.16 \times 10^{19}$ \\
\hline Equatorial radius of Jupiter, $R_{e}$ & $\mathrm{~m}$ & & & $7.15 \times 10^{7}$ \\
\hline $\begin{array}{l}\text { Magnetic induction on the Jupiter's equator } \boldsymbol{B}_{e z}^{e} \\
\text { (for the sectoral circle) }\end{array}$ & $\mathrm{T}$ & $\boldsymbol{B}_{e z}^{e}=\frac{\mu_{0} e n S_{e z}}{4 \pi\left(R_{e}-R_{e z}\right)^{2}} \sin \alpha$ & (16) & $3.14 \times 10^{-2}$ \\
\hline $\begin{array}{l}\text { Thickness of the } \mathrm{Me}_{\mathrm{H}} \text { layer, involved into heightened } \\
\text { rotation with the equatorial band, } d_{e z}\end{array}$ & $\mathrm{~m}$ & & & 250 \\
\hline Section of the spherical laminar circle $S_{e z}^{\prime}$ & $\mathrm{m}^{2}$ & $S_{e z}^{\prime}=L_{S} d_{e z}$ & & $4.63 \times 10^{9}$ \\
\hline Relative velocity of the plane plate with the section $S_{e z}^{\prime}, V$ & $\mathrm{~m} / \mathrm{s}$ & $v=2 \pi R_{\mathrm{Me}_{\mathrm{H}}}\left(\frac{1}{T_{2}}-\frac{1}{T_{1}}\right)$ & & 887 \\
\hline Current density, $\boldsymbol{j}_{e z}^{\prime}$ & $\mathrm{A} / \mathrm{m}^{2}$ & $\boldsymbol{j}_{e z}^{\prime}=\rho v$ & (12) & $6.0 \times 10^{5}$ \\
\hline Total current through the sector $S_{e z}^{\prime}$ section, $I_{e z}^{\prime}$ & A & $\boldsymbol{I}_{e z}^{\prime}=\boldsymbol{j}_{e z}^{\prime} S_{e z}^{\prime}$ & (14) & $2.78 \times 10^{15}$ \\
\hline Magnetic induction on the Jupiter's equator $\boldsymbol{B}_{d}^{e}$ (for the plate) & $\mathrm{T}$ & $\boldsymbol{B}_{d}^{e}=\frac{\mu_{0} e n S_{e z}^{\prime}}{4 \pi\left(R_{e}-R_{\mathrm{Me}_{\mathrm{H}}}\right)^{2}} \sin \alpha$ & (17) & $1.42 \times 10^{-6}$ \\
\hline
\end{tabular}

Jupiter's magnetic field $\boldsymbol{B}_{j u}$ should have a trapezoidal or a "sauser" form.

Previously there was an opinion on the Jupiter's magnetic field structure that the reason why the field lines are stretched to the $20 \mathrm{Rj}$ distance, forming the magnetic field structure as a thin pancake is that both the centrifugal force and the thermal pressure of the plasma affect the plasma [42]. Our calculations show another reason, though it can be an addition to the said opinion.

Besides, if we look at the vector diagrams $D_{1} B_{1} C_{1}$ and $D_{2} B_{2} C_{2}$ it gets clear that the $\boldsymbol{B}_{1}$ и $\boldsymbol{B}_{2}$ vectors cause "pulling out" field lines with higher energy in the North pole area. At the same time the $\boldsymbol{B}_{3}$ and $\boldsymbol{B}_{4}$ vectors cause "dragging in" field lines 


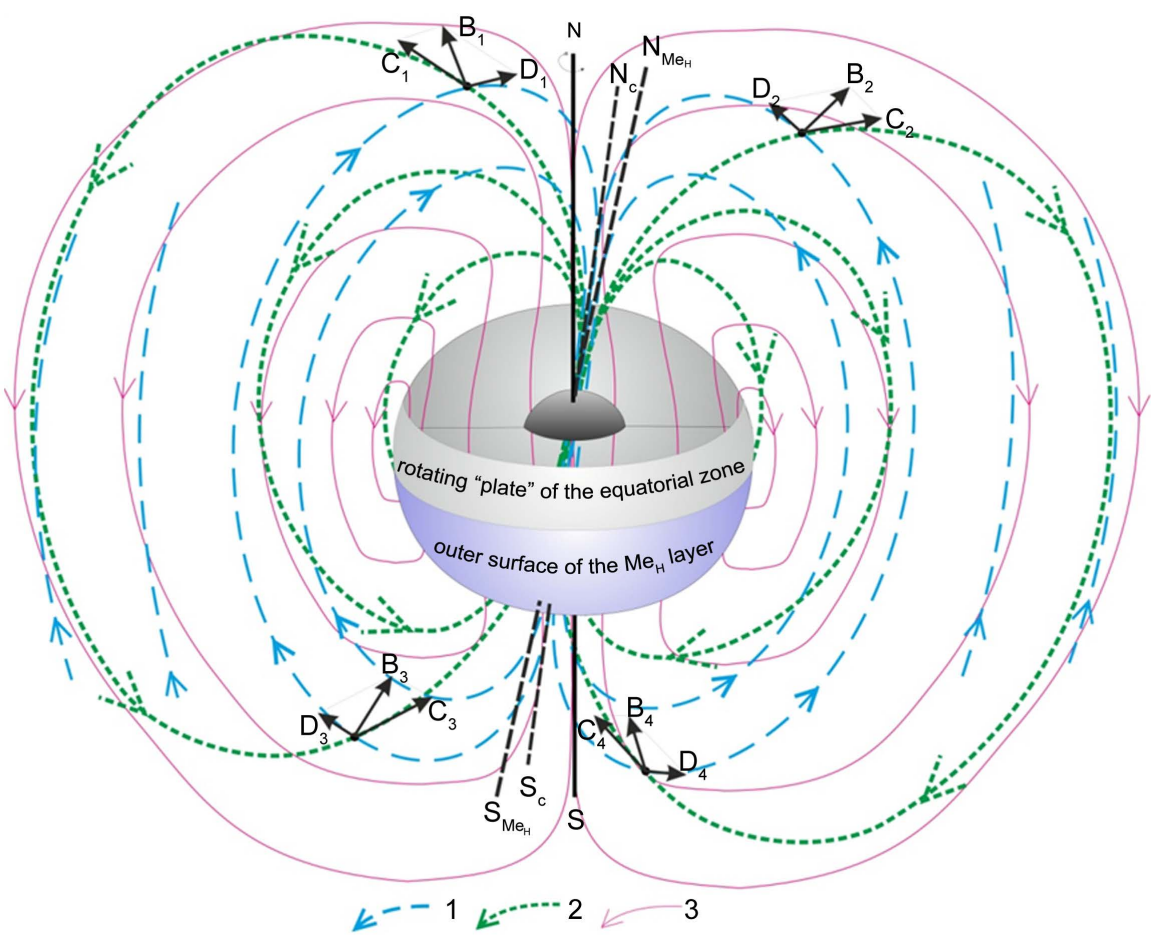

Figure 3. The combined magnetic field of Jupiter of its three sources: the liquid metal hydrogen layer, the metal core and the circle of the sectoral plate. Magnetic induction lines: 1 -of the liquid metal hydrogen layer, 2-of the metal core, 3-of the circle of the sectoral plate.

with lower energy through the South pole. That is why the value of magnetic induction at the Jupiter's North pole is expected to be higher while the one at the South pole must be lower, i.e. there must be pseudo anisotropy of the planet's magnetic field. The latter coincides with the known measurements of the magnetic field's densities at the planet's poles, which are $14 \mathrm{G}$ at the North pole and $10.7 \mathrm{G}$ at the South pole [32].

\section{Evaluation of How Main Forming Parameters $\Delta T_{C}, R_{C}, \sigma$ Affect the Value of a Planet's Magnetic Field}

Due to lack of accurate knowledge of main forming parameters' values $\Delta T_{O} R_{O}$ $\sigma$, oscillation range of the Jupiter's magnetic field intensity in dependence of those parameters' values changes should be carried on. Those very parameters determine the value of density $j$ and amperage $I$, which form the needed intensity of the planet's magnetic field $\boldsymbol{B}$. When there is no temperature difference in the core there are no thermo e.m.f and, accordingly, there are no thermocurrents, even if the core is metal. Both current density $j$ and amperage $I$ cannot be enough to maintain the needed level of the magnetic field $B$ at low electrical conductivity $\sigma$, even if $\Delta T_{C}$ and $R_{C}$ are of great value. At the same time importance of the metal core radius $R_{C}$ increases significantly only when the quantity of electrons in the core (or in other conductive shells) is enough to generate the needed flow of thermocurrents, which generate the corresponding magnetic 
fields.

The calculations of the studied parameters are brought together to the Table 4. The algorithm of the calculations was as follows: when, for instance, the first parameter of the discretization value changed, the magnetic induction $\boldsymbol{B}_{C}^{p}$ was fully recalculated. That allowed to take into consideration effects of every discrete on the whole system, making the evaluation of each parameter of the system objective.

Table 4 shows that $\boldsymbol{B}_{C}^{p}$ increases proportionally at uniform increase of temperature difference $\Delta T_{C}$ with $1000^{\circ} \mathrm{C}$ step. If discretization step decrease to, for instance, $100 \mathrm{~K}$ (deviation 4) then proportionality for $\boldsymbol{B}_{C}^{p}$ stays the same and has mutual linear connection $\boldsymbol{B}_{C}^{p}=0.0003 \Delta T_{C}+0.0025$ at every discretization of $\Delta T_{C}$ As the radius $R_{C}$ increases linearly, the magnetic induction increases according to quadratic polynomial $\boldsymbol{B}_{C}^{p}=3 \times 10^{-5} \times R_{C}^{2}+0.0005 R_{C}+0.0023$, i.e. at every new magnitude of $R_{C}$ the value of $\boldsymbol{B}_{C}^{p}$ always gets more than two times larger (or smaller). Here is also a connection between electroconductivity of metals and magnetic induction according to the dependence: $\boldsymbol{B}_{C}^{p}=0.0009 \sigma$ +0.0019 .

Table 4. Evaluation of affecting the Jupiter's magnetic field at incorrect setting of main parameters: $\Delta T_{O} R_{O} \sigma$.

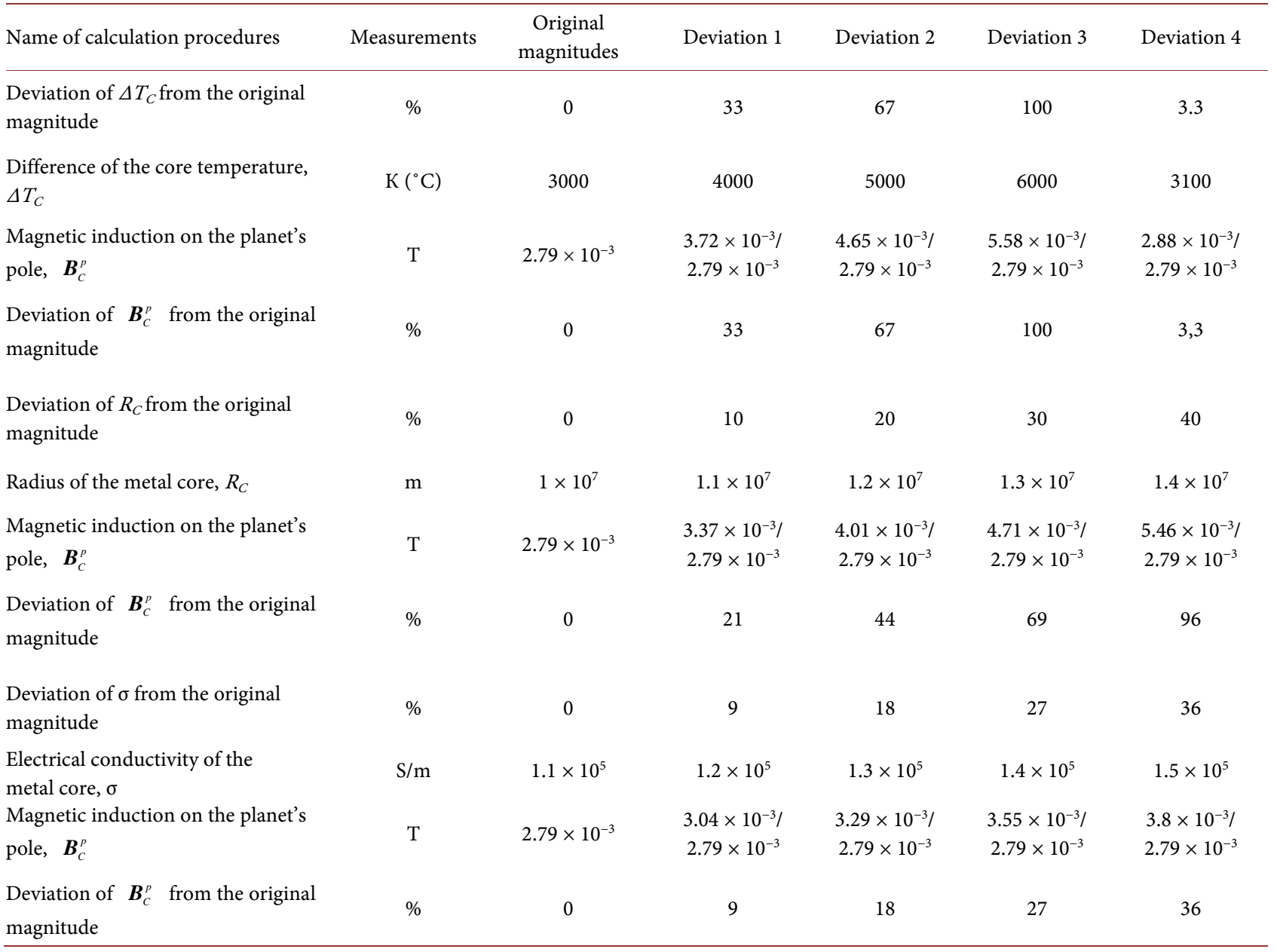


The defined connections show that the magnetic field intensity is closely connected to the main forming parameters-even a slight change of them enhance (or reduce) the Jupiter's magnetic induction $\boldsymbol{B}_{C}^{p}$ instantly. So, if you need the calculated magnitude of magnetic induction $\boldsymbol{B}_{C}^{p}$ coincide accurately with the one measured by spacecrafts $\boldsymbol{B}_{j u}^{p}$, you have to sort out all the forming parameters $\Delta T_{C}, R_{C}, \sigma$ when there is no accurate data of their values. Calculations show that sorting out helps to exclude formal (deliberate) results with changes of one or another parameter. When the quality $\boldsymbol{B}_{C}^{p}=\boldsymbol{B}_{j u}^{p}$ for the forming parameters is achieved, their optimal magnitudes can be defined.

The conclusion is that in the future if there are magnitudes of a planet's magnetic field elements of any exactness, then solving the inverse problem lets one predict the inner structure of that planet with the same exactness, but only for its electrically conductive elements (shells, layers, zones).

\section{Conclusions}

The approbation of the suggested method of calculation magnetic fields of planets, of Jupiter in particular, results in the following:

- Autonomous sources of the Jupiter's magnetic field are the spherical liquid metal hydrogen layer, the metal core and the spherical circle of liquid metal hydrogen external part plate rotating in the alignment of Jupiter's equatorial band with maximal speed.

- The Jupiter's main magnetic field is the magnetic field of the metal core $\boldsymbol{B}_{C}$, the main additional one is the magnetic field of liquid metal hydrogen layer $\boldsymbol{B}_{\mathrm{Me}_{\mathrm{H}}}$, the accompanying one is the local magnetic field of the $\mathrm{Me}_{\mathrm{H}}$ layer's circular band (plate) $\boldsymbol{B}_{d}$.

- Orientation of main magnetic field $\boldsymbol{B}_{C}$ poles fits Jupiter's geographical poles.

Besides, the performed calculations made it possible to evaluate the most possible magnitude range of electroconductivity of both liquid metal hydrogen layer and the Jupiter's metal core for the first time. The reason why the Jupiter's magnetic fields orientation is opposite to the Earth's one is also explained. For the first time there is a supposition that cores of electronically conducting planets, and even stars, have universal structures, because there is always an intermediary radiation band with most heated and melted masses of matter between the "core" and the "mantel".

Even though there are significant differences between the existing models of the Jupiter's inner structure, the introduced method of calculating magnetic fields of planets turned out to be not only working for Jupiter, but able to give a reasonable explanation to a lot of obscure questions regarding the structure of its complicated magnetic field. The results of the performed mathematical modeling are expected to be confirmed by the Jupiter Polar Orbiter Juno soon. The inner structure of the planet, regarding its electrical conductivity elements (the metal core and the liquid metal hydrogen layer), is going to be specified signifi- 
cantly with help of the expected detailed data and the introduced method.

In conclusion, it could be considered that the method of calculating planets' magnetic fields generally corresponds the meaning of the thermoelectrical model of those planets' magnetic fields. The latter, in comparison to the magnetodynamo model, has undoubted advantages, because of its simpler physical and mathematical description. The thermoelectrical model can also explain some peculiarities of the Earth and Jupiter's magnetic fields conduct.

\section{Acknowledgements}

Thanks to Abramovich S.A. for checking mathematical calculations and Proskurnina T.V. for efforts to translate the manuscript to English.

\section{Additional Information}

The manuscript "To the question about the nature and structure of Jupiter's magnetic field" was not published in any magazine and it is not being edited in any editorial office.

An article close by meaning was published in 2016:

Dmitriev A.N. A New Look on the Nature of the Earth's Magnetic Field//IOP Conf. Series: Earth and Environmental Science 44 (2016) 022001.

https://doi.org/10.1088/1755-1315/44/2/022001

I made the manuscript on my own in the Tyumen Industrial University, where I am working. Here is no competing financial or any other interest of any organization as I did not get any subsidies, grants or ordinary shares. I, A.N. Dmitriev, am the only author of the manuscript and there is no legal claim to me from anyone.

The manuscript author, A.N. Dmitriev.

\section{References}

[1] Dmitriev, A.N. (2016) A New Look on the Nature of the Earth's Magnetic Field. IOP Conference Series: Earth and Environmental Science, 44, Article ID: 022001. https://doi.org/10.1088/1755-1315/44/2/022001

[2] Smith, E.J., et al. (1974) The Planetary Magnetic Field and Magnetosphere of Jupiter: Pioneer 10. Journal of Geophysical Research, 79, 3501-3513. https://doi.org/10.1029/JA079i025p03501

[3] Smith, E.J., et al. (1975) Jupiter's Magnetic Field, Magnetosphere and Interaction with the Solar Wind: Pioneer 11. Science, 188, 451. https://doi.org/10.1126/science.188.4187.451

[4] Acuna, M.H. and Ness, N.F. (1976a) The Main Magnetic Field of Jupiter. Journal of Geophysical Research, 81, 2917-2922. https://doi.org/10.1029/JA081i016p02917

[5] Acuna, M.H. and Ness, N.F. (1976b) The Magnetic Field of Jupiter. In: McCormac, B.M., Ed., Magnetospheric Particles and Fields, Proceedings of the Summer Advanced Study School, Austria, 4-15 August 1975, 311-323.

[6] Russell, C.T. (1993a) Magnetic Fields of the Terrestrial Planets. Journal of Geophysical Research, 98, 18681-18695. https://doi.org/10.1029/93JE00981 
[7] Elkins-Tanton, L.T. (2011) Jupiter and Saturn. Chelser House Publishers, New York, 276.

[8] Khurana, K.K., et al. (2004) The Configuration of Jupiter's Magnetosphere. In: Bagenal, F., Dowling, T.E. and McKinnon, W.B., Eds., Jupiter. The Planet, Satellites and Magnetosphere, Cambridge University Press, Cambridge.

http://www.igpp.ucla.edu/people/mkivelson/Publications/279-Ch24.pdf

[9] Militzer, B., et al. (2008) A Massive Core in Jupiter Predicted from First-Principles Simulations. Astrophysical Journal Letters, 688, L45-L48. https://doi.org/10.1086/594364

[10] Hubbard, W.B. and Militzer, B. (2016) A Preliminary Jupiter Model. Astrophysical Journal, 820, $13 \mathrm{p}$.

[11] Shvets, V.T. and Kozitskii, S.V. (2013) Electroconductivity and Thermopower of Metallic Helium. Physics of Solid Body, 55, 625-630.

[12] Ternovoi, V.Ya., et al. (2004) Experimental Determination of Transition of Jupiter Atmosphere to Conducting State. Journal of Experimental and Theoretical Physics Letters, 79, 6-9. https://doi.org/10.1134/1.1675910

[13] Kuskov, O.L., Dorofeeva, V.A., Kronrod, V.A. and Makalkin, A.B. (2009) Jupiter and Saturn's Systems: Formation, Composition and Inner Structure of Large Satellites. URSS, 576.

[14] Gudkova, T.V. and Zharkov, V.N. (1999) Models of Jupiter and Saturn after Galileo Mission. Planetary and Space Science, 47, 1201-1210. https://doi.org/10.1016/S0032-0633(99)00044-6

[15] Kalashnikov, S.G. (1983) Electricity. Nauka, Moscow, 416.

[16] Saveliev, I.V. (1998) General Physics Classes, Vol. 2. Electricity. Nauka, Moscow, 432.

[17] Lifshits, I.M., Azbel, M.Y. and Kaganov, M.I. (1971) Electron Theory of Metals. Nauka, Moscow, 416.

[18] Matveev, A.N. (1983) Electricity and Magnetism. Visshaya Shkola, Moscow, 464.

[19] Tyushev, A.N. (2011) Physics Lectures, Part 5. Quantum Physics. SGGA, Novosibirsk, 167.

[20] Pavlov, P.V. and Khokhlov, A.F. (2000) Physics of Solid Body: Textbook. Visshaya School, Moscow, 494.

[21] Zhuravlev, V.A. (2002) Lectures on Quantum Theory of Metals. Institut kompiuternykh issledovanii, Moscow, 240.

[22] Züttel, A., Borgschulte, A. and Schlapbach, L. (2008) Hydrogen as a Future Energy Carrier. Wiley-VCH Verlag GmbH \& Co. KGaA, Berlin.

https://doi.org/10.1002/9783527622894

[23] Russell, C.T. (1993b) Planetary Magnetospheres. Reports on Progress in Physics, 56, 687-732. https://doi.org/10.1088/0034-4885/56/6/001

[24] Ashcroft, N.W. (1968) Metallic Hydrogen: A High-Temperature Superconductor? Physical Review Letters, 21, 1748. https://doi.org/10.1103/PhysRevLett.21.1748

[25] Ashcroft, N.W. (2000) The Hydrogen Liquids. Journal of Physics: Condensed Matter, 12, A129-A139. https://doi.org/10.1088/0953-8984/12/8A/314

[26] Bonev, S.A., Schwegler, A., Ogitsu, T. and Galli, G. (2004) A Quantum Fluid of Metallic Hydrogen Suggested by First-Principles Calculations. Nature, 431, 669-672. https://doi.org/10.1038/nature02968

[27] Babaev, E. and Ashcroft, N.W. (2007) Violation of the London Law and Onsag- 
er-Feynman Quantization in Multicomponent Superconductors. Nature Physics, 3. 530-533. https://doi.org/10.1038/nphys646

[28] Blanc, M., Bolton, S., Bradle, J., et al. (2002) Magnetospheric and Plasma Science with Cassini-Huygens. Space Science Reviews, 104, 253-346. https://doi.org/10.1023/A:1023605110711

[29] Alexeev, I.I. and Belenkaya, E.S. (2005) Modeling of the Jovian Magnetosphere. Annales Geophysicae, 23, 809-826. https://doi.org/10.5194/angeo-23-809-2005

[30] Smith, E.J., Davis, L. Jr., Jones, D.E., et al. (1975) Jupiter's Magnetic Field. Magnetosphere, and Interaction with the Solar Wind: Pioneer 11. Science, 188, 451-455. https://doi.org/10.1126/science.188.4187.451

[31] Web Page References (2016) Jovian Magnetosphere. http://nssdc.gsfc.nasa.gov/planetary/factsheet/jupiterfact.html

[32] Jupiter (2010) http://astro.websib.ru/sun/Jupiter

[33] Zharkov, V.N. (1983) Inner Structure of Earth and Other Planets. Nauka, Moscow, 416.

[34] Magnitskii, V.A. (2006) Earth’s Inner Structure and Physics. Nauka, Moscow, 389.

[35] Kuznetzov, V.V. (2008) Introduction to Hot Earth Physics. IKIR, 366.

[36] Li, Y., Vočadlo, L. Brodholt, J. and Wood, I.G. (2016) Thermoelasticity of $\mathrm{Fe}_{7} \mathrm{C}_{3}$ under Inner-Core Conditions. Journal of Geophysical Research: Solid Earth, 121, 5828-5837. https://doi.org/10.1002/2016JB013155

[37] Sanders, R. and Relations, M. (2008) Jupiter's Rocky Core Bigger and Icier, Model Predicts. http://www.berkeley.edu/news/media/releases/2008/11/25_core.shtml

[38] Loper, D.E. (1984) Structure of the Core and Lower Mantle. Advances in Geophysics, 26, 1-34. https://doi.org/10.1016/S0065-2687(08)60243-5

[39] Dunlop, S. (1985) Astronomy: A Step-by-Step Guide to the Night Sky. Collier Books, New York, 192.

[40] Belkin, I.K. (1984) Electric and Magnetic Fields. Kvant, No. 3. 28-31.

[41] Ridpath, I. (2003) Norton's Star Atlas. 20th Edition, Dutton Adult, New York, 208.

[42] Russell, C.T. (2001) The Dynamics of Planetary Magnetospheres. Planetary and Space Science, 49, 1005-1030. https://doi.org/10.1016/S0032-0633(01)00017-4

Submit or recommend next manuscript to SCIRP and we will provide best service for you:

Accepting pre-submission inquiries through Email, Facebook, LinkedIn, Twitter, etc. A wide selection of journals (inclusive of 9 subjects, more than 200 journals)

Providing 24-hour high-quality service

User-friendly online submission system

Fair and swift peer-review system

Efficient typesetting and proofreading procedure

Display of the result of downloads and visits, as well as the number of cited articles

Maximum dissemination of your research work

Submit your manuscript at: http://papersubmission.scirp.org/

Or contact ijg@scirp.org 